\title{
Effects of different combinations of dietary starch and non-starch polysaccharides on intestinal functions, and lipid and glucose metabolism in weaned pigs
}

\author{
H. Zhou, D.-w. Chen, J. He, X.-b. Mao, J. Yu, P. Zheng, J.-q. Luo, Y.-h. Luo, \\ H. Yan and B. Yu ${ }^{1}$ \\ Sichuan Agricultural University, Institute of Animal Nutrition, \\ Key Laboratory for Animal Disease-Resistance Nutrition of Ministry of Education, Chengdu, Sichuan 611130, China
}

KEY WORDS: carbohydrates combination, intestinal functions, lipid metabolism, glucose metabolism, weaned pigs

Received: $\quad 14$ April 2020

Revised: 20 May 2020

Accepted: 16 September 2020

${ }^{1}$ Corresponding author:

e-mail: ybingtian@163.com

\begin{abstract}
The aim of the present study was to investigate the effects of different combinations of dietary starch and non-starch polysaccharides (NSP) on intestinal functions, and lipid and glucose metabolism in pigs. Fifty-four weaned pigs weighing $6.71 \pm 0.52 \mathrm{~kg}$ were randomly assigned according to body weight and sex to 3 treatments with 6 replicates per treatment and 3 pigs per replicate, and were fed: $T 1$ diet containing starch with amylose/amylopectin (AM/AP) ratio of 1:1 and NSP 3\% (a mixture of inulin and cellulose in a ratio 1:1), T2 diet with starch of AM/AP ratio 2:1 and NSP $1 \%$ or T3 diet containing starch with AM/AP ratio of $1: 2$ and NSP $2 \%$. Pigs were fed experimental diets for 28 days. It was shown that in animals fed T1 diet mRNA expression of glucagonlike peptide-2, zonula occludens 1 and occludin $(P<0.05)$ were up-regulated and tended to be increased the mRNA level of insulin-like growth factor-1 $(P=0.06)$ in colon, the activity of lactase in jejunum was increased $(P<0.05)$, mRNA expression of insulin receptor substrate 1 and glucose-6-phosphatase in liver were improved $(P<0.05)$, and the activity of lipoprotein lipase $(P<0.05)$ was decreased and the activity of malate dehydrogenase tended to be enhanced $(P=0.07$ ) in longissimus dorsi muscle. Feeding T1 diet promoted the intestinal functions and improved to some extent lipid and glucose metabolism in pigs. So, carbohydrates combination of starch with AM/AP ratio of 1:1 and NSP $3 \%$ can be recommended for weaned pigs.
\end{abstract}

\section{Introduction}

Polymeric carbohydrates, starch and non-starch polysaccharide (NSP), are the main ingredients in the diets and are the major energy contributors for pigs (Bach Knudsen, 2011). Noteworthy, types of starch, from their nature, differ in an amylose to amylopectin ratio (AM/AP). As the molecular configuration and structure are different, amylopectin-rich starch is easily digested, while amylose-rich starch not (Singh et al., 2010). Indeed, it was previously shown that feed intake and feed efficiency in pigs were reduced along with increasing amylose content (Regmi et al., 2011). Additionally, amylopectin could lead to a rapid increase in glucose and insulin concentrations relative to amylose (Behall and Scholfield, 2005; Regmi et al., 2010). Moreover, it was indicated that higher level of amylopectin negatively influences the hepatic lipid deposit in pigs and should be avoided in the diet composition (Yang et al., 2018). Yet, emerging evidences indicated that starch with relative higher $\mathrm{AM} / \mathrm{AP}$ ratio increased the average daily gain and feed efficiency in finishing pigs (Li et al., 2017; Wang et al., 2019), and tended to decrease the average back 
fat thickness (Wang et al., 2019). Meanwhile, starch with a higher AM/AP ratio improved intestinal morphology and promoted expression of genes related to intestinal function in piglets (Xiang et al., 2011; Han et al., 2012), and decreased the mRNA levels of genes related to fat synthesis in liver $(\mathrm{He}$ et al., 2010). Dietary fibre, chemically mainly made up of NSP, promotes gastrointestinal health both in humans and animals (Bosaeus, 2004; Kumar et al., 2012). Likewise, it is a critical ingredient influencing the intestinal development and health of pigs. In the literature it is shown that dietary fibre enhances the intestinal morphology, barrier function and reduces diarrhoea incidences in piglets (Lindberg et al., 2014; Chen et al., 2015; Wu et al., 2018). Noteworthy, piglets fed both soluble and insoluble fibre (ratio 1:1) had better nutrients absorption and gut barrier functioning than those fed one kind of fibre (Chen et al., 2019). Meanwhile, dietary fibre could reduce liver fat deposition by regulating the expression of genes related to lipid metabolism (Han et al., 2016). Furthermore, fermentable carbohydrates (e.g., resistant starch and NSP) were used by hindgut microflora as fermentative substrate (Aumiller et al., 2015; Jha and Berrocoso, 2015). Under the anaerobic conditions, undigested carbohydrates were fermented mainly to short-chain fatty acids (SCFAs), mainly acetic acid, propionic acid and butyric acid (Flint et al., 2012). SCFAs play a crucial role in regulating intestinal health, and lipid and glucose metabolism (Ichimura et al., 2009).

Consequently, starch with various AM/AP ratios exhibited different physiological responses to growth performance, intestinal functioning and lipid metabolism. In addition, dietary fibre could promote the gut health and decrease fat deposition in the liver. Effects of dietary fibre and starch (in the form of resistant starch) on intestinal functions, and lipid and glucose metabolism may be regulated by SCFAs. In traditional swine nutrition, analyses of starch and fibre have focused on measuring its quantity. However, the information of carbohydrates quality for pigs are poorly understood. Notably, we have observed that the combination of starch with $\mathrm{AM} / \mathrm{AP}$ ratio of $1: 1$ and NSP 3\% (a mixture of inulin and cellulose in ratio 1:1) markedly improved the growth performance and nutrients digestibility, tended to reduce diarrhoea incidences, significantly increased the concentration of butyrate in serum and reduced the content of acetate and propionate in caecum and colon (unpublished data). Likewise, in pigs fed diet with this combination the abundance of Firmicutes was significantly increased, therefore fibre degradation and production of butyrate can be promoted (Louis and Flint, 2017). So, we hypothesized that the diet containing starch with $\mathrm{AM} / \mathrm{AP}$ ratio of $1: 1$ and NSP 3\% may promote intestinal functions, and improve lipid and glucose metabolism in pigs. Therefore, the current study was conducted to evaluate the effects of different combinations of dietary starch and NSP on intestinal functioning, and lipid and glucose metabolism in weaned pigs.

\section{Material and methods}

\section{Animal care}

Experimental proposals and procedures used in the present experiment were conducted in accordance with the Animal Care and Use Committee of Sichuan Agricultural University (Ya'an, China) under permit number DKY-B20131704.

\section{Animals, housing and dietary treatments}

In total, 54 crossbred Duroc $\times($ Landrace $\times$ Yorkshire) pigs weaned at $21 \pm 1$ day were provided by a commercial farm, then were housed in a temperature-controlled nursery house with completely slotted floors and fed a common pre-starter diet during a 5-day adaptation period. Pigs with an initial body weight (BW) of $6.71 \pm 0.52 \mathrm{~kg}$ were randomly assigned to 1 of 3 dietary treatments with 6 replicate pens ( 3 pens were barrows and other 3 pens were gilts) per treatment and 3 pigs per pen. Each pen $(1.8 \times 2.5 \mathrm{~m})$ was equipped with a single nipple waterer and a 1-sided feeder. Pigs were allowed ad libitum access to water and feed, and feed intake per pen was measured daily to calculate average daily feed intake. Room temperature initially was set at $28{ }^{\circ} \mathrm{C}$ for the first week and gradually reduced to $25^{\circ} \mathrm{C}$ by the end of the experiment.

The experimental diets were based on maize and soybean meal. The compositions of ingredients, and calculated and analysed nutrients of diets are presented in Table 1 and Table 2, respectively. The 3 dietary treatments were as follows: T1 diet supplemented with high amylose concentration and conventional maize starch (the $\mathrm{AM} / \mathrm{AP}$ ratio of $1: 1$ ) and $3 \%$ NSP (a mixture of inulin and cellulose in a 1:1 ratio); T2 diet supplemented with high concentration of amylose maize starch (the AM/AP ratio of 2:1) and 1\% NSP; T3 diet supplemented with high concentration of amylopectin maize starch (the AM/AP ratio of 1:2) and 2\% NSP. Diets were formulated to meet or exceed the National Research Council (NRC, 2012) nutrient requirements for pigs weighing $10-20 \mathrm{~kg}$. The purity of amylose, amylopectin, inulin (the degree of polymerization of 2-60, and an average 
Table 1. Ingredient composition of experimental diets (as-fed basis)

\begin{tabular}{|c|c|c|c|}
\hline \multirow[t]{2}{*}{ Ingredients, \% } & \multicolumn{3}{|c|}{$\begin{array}{l}\text { Diets with different combinations } \\
\text { of carbohydrates }\end{array}$} \\
\hline & $\mathrm{T} 1$ & T2 & T3 \\
\hline Maize & 14.1 & 16.75 & 15.37 \\
\hline Puffed maize & 10 & 10 & 10 \\
\hline Soybean meal & 13.65 & 13.2 & 13.43 \\
\hline Puffing of soybean & 7 & 7 & 7 \\
\hline Soy protein concentrate & 5 & 5 & 5 \\
\hline Whey powder & 5 & 5 & 5 \\
\hline Fish meal & 3 & 3 & 3 \\
\hline Plasma protein powder & 3 & 3 & 3 \\
\hline Glucose & 2 & 2 & 2 \\
\hline Soybean oil & 1.4 & 0.2 & 0.8 \\
\hline Conventional maize starch & 12.6 & & \\
\hline High amylose maize starch & 17.1 & 30.7 & 3.8 \\
\hline High amylopectin maize starch & & & 26.45 \\
\hline Cellulose & 1.5 & 0.5 & 1 \\
\hline Inulin & 1.5 & 0.5 & 1 \\
\hline Limestone & 0.45 & 0.45 & 0.45 \\
\hline Dicalcium phosphate & 1.25 & 1.25 & 1.25 \\
\hline L-Lysine-HCl, $78 \%$ & 0.29 & 0.29 & 0.29 \\
\hline DL-Methionine, 99\% & 0.12 & 0.12 & 0.12 \\
\hline L-Threonine, 98.5\% & 0.13 & 0.13 & 0.13 \\
\hline L-Tryptophan, 98\% & 0.01 & 0.01 & 0.01 \\
\hline Mineral premix ${ }^{1}$ & 0.45 & 0.45 & 0.45 \\
\hline Vitamin premix ${ }^{2}$ & 0.05 & 0.05 & 0.05 \\
\hline $\mathrm{NaCl}$ & 0.25 & 0.25 & 0.25 \\
\hline Choline chloride & 0.15 & 0.15 & 0.15 \\
\hline Total & 100.00 & 100.00 & 100.00 \\
\hline
\end{tabular}

$\mathrm{T} 1$ - diet containing starch with amylose/amylopectin (AM/AP) ratio of 1:1 and NSP $3 \%$ (a mixture of inulin and cellulose in a ratio 1:1); T2 - diet containing starch with AM/AP ratio of 2:1 and NSP 1\%; T3 - diet containing starch with AM/AP ratio of $1: 2$ and NSP $2 \%$;. ${ }^{1}$ provided per kg of diet, IU: vit. A 8000 , vit. $D_{3} 2000$, vit. E 20; mg: vit. $B_{1} 1.5$, vit. $B_{2} 5.6$, vit. $B_{12} 0.02$, vit. $B_{6} 1.5$, vit. $K 32$, calcium pantotenate 10 , nicotinic acid 15 , biotin 0.1 , folic acid 0.6 ; ${ }^{2}$ provided per kg of diet, mg: Fe 100 as $\mathrm{FeSO}_{4}, \mathrm{Cu} 20$ as $\mathrm{CuSO}_{4} \cdot 5 \mathrm{H}_{2} \mathrm{O}, \mathrm{Zn} 100$ as $\mathrm{ZnSO}_{4}, \mathrm{Mn} 60$ as $\mathrm{MnSO}_{4}, \mathrm{I} 0.3$ as KI, Se 0.3 as $^{\mathrm{Na}_{2} \mathrm{SeO}_{3}}$

of 12) and cellulose was $68.5,95,85$ and $99 \%$, respectively, and the substances were obtained from Kang Biological Products Co., Ltd. (Chicago, USA), Fuyang Biotechnology Co., Ltd. (Dezhou, China), VILOF Group Co., Ltd. (Beijing, China) and Tianli Medical Supplements Co., Ltd. (Qufu, China), respectively. No antibiotics were used in any diet.

\section{Sampling and measurements}

On day 28 of experiment, one pig with an average BW of each pen was chosen and euthanized by intravenous injection of sodium pentobarbital ( $200 \mathrm{mg} / \mathrm{kg} \mathrm{BW}$ ) according to Chen et al. (2013). The abdomen was opened to remove the jejunum, colon, liver and longissimus dorsi muscle immediately. The jejunal mucosa was collected by scraping the intestinal wall with a glass microscope slide, immediately frozen in liquid nitrogen and stored at
Table 2. Calculated nutritional value of experimental diets (as-fed basis)

\begin{tabular}{lccc}
\hline \multirow{4}{*}{ Nutrients } & \multicolumn{3}{c}{ Diets with different combinations } \\
& of carbohydrates & \\
\cline { 2 - 4 } & T1 & T2 & T3 \\
\hline Calculated value & & & \\
crude protein, \% & 19.0 & 19.0 & 19.0 \\
net energy, kcal/kg & 2645 & 2645 & 2645 \\
crude fibre, \% & 3.91 & 2.23 & 3.08 \\
SID-Lysine $1, \%$ & 1.23 & 1.23 & 1.23 \\
SID-Methionine, \% & 0.36 & 0.36 & 0.36 \\
SID-Threonine, \% & 0.73 & 0.73 & 0.73 \\
SID-Tryptophan, \% & 0.20 & 0.20 & 0.20 \\
calcium, \% & 0.70 & 0.70 & 0.70 \\
available phosphorus, \% & 0.45 & 0.45 & 0.45 \\
Analysed values & & & \\
crude protein, \% & 20.23 & 20.46 & 20.57 \\
gross energy, kcal/kg & 3979.6 & 3921.8 & 3916.5 \\
amylose content ${ }^{2}, \%$ & 49.86 & 68.11 & 35.89 \\
amylopectin content ${ }^{2}, \%$ & 50.14 & 31.89 & 64.11 \\
amylose/amylopectin & 0.99 & 2.14 & 0.56 \\
\hline
\end{tabular}

T1, T2, T3 - see Table 1; ${ }^{1}$ values for standardized ileal concentrations of amino acids were estimated using standardized ileal digestible (SID) coefficients provided by NRC (2012), amino acids data and feed composition data of net energy and crude fire were also obtained from this source; ${ }^{2}$ contents of amylose and amylopectin were measured using commercial kits (Megazyme) obtained from Bray Business Park (Wicklow, Ireland)

$-80{ }^{\circ} \mathrm{C}$ until the analysis of the activities of digestive and absorptive enzymes. Liver and longissimus dorsi muscle samples were collected to detect the activities of enzymes involved in lipid metabolism. Additionally, intestinal segment of jejunum and colon, and a small cube of liver and longissimus dorsi muscle were collected and immediately frozen at $-80^{\circ} \mathrm{C}$ for quantitative real-time PCR analysis.

\section{Chemical analysis}

The experimental diets were sampled once and stored at $-20{ }^{\circ} \mathrm{C}$ for chemical analysis. Diet samples were ground through a 1-mm screen and analysed for crude protein (CP) according to the standard methods (AOAC International, 1995). The gross energy (GE) of diet samples were determined using an adiabatic oxygen bomb calorimetry (Parr Instrument Co., Moline, IL, USA). The content of amylose and amylopectin were measured using commercial kits of Megazyme (Bray Business Park, Wicklow, Ireland) according to the manufacturer's instructions.

\section{Determination of enzyme activity}

For enzyme activity assessment, about 1-g frozen samples of jejunum mucosa, liver and longissimus dorsi muscle were homogenized in ice-cold saline solution $(1: 9, \mathrm{wt} / \mathrm{vol})$ and then centrifuged at $3000 \mathrm{~g}$ for $15 \mathrm{~min}$ at $4{ }^{\circ} \mathrm{C}$. The supernatant was collected for further analysis. The activities of trypsin, amylase, lactase, sucrase, 
Table 3. Primer sequences used for real-time quantitative PCR

\begin{tabular}{lllll}
\hline Target gene & Forward primer 5'-3' & Reverse primer 5'-3' & $\begin{array}{l}\text { Product } \\
\text { length, bp }\end{array}$ & $\begin{array}{l}\text { Accession } \\
\text { number }\end{array}$ \\
\hline ACTB & TCTGGCACCACACCTTCT & TGATCTGGGTCATCTTCTCAC & 114 & XM_021086047.1 \\
GLP2 & ACTCACAGGGCACGTTTACCA & AGGTCCCTTCAGCATGTCTCT & 149 & NM_005671883.1 \\
IGF1 & CTGAGGAGGCTGGAGATGTACT & CCTGAACTCCCTCTACTTGTGTTC & 137 & NM_214256.1 \\
OCLN & CAGGTGCACCCTCCAGATTG & GGACTTTCAAGAGGCCTGGAT & 110 & NM_001163647.2 \\
Z01 & CTGAGGGATTGGGCAGGAA & TCACCAAAGGACTCAGCAGG & 105 & XM_021098827.1 \\
MUC2 & GGTCATGCTGGAGCTGGACAGT & TGCCTCCTCGGGGTCGTCAC & 181 & XM_021082584.1 \\
INSR & CTGCG TCACTTCACTGGCTA & TCATCTGCCTTGGCTTCAGG & 122 & XM_021083940.1 \\
IRS1 & TGGATGATTCTGTGG TGGCC & CTGATGGGGTTGAGCAGTT & 124 & NM_001244489.1 \\
PIK3C3 & GCTGTGCTGGATATTGCGTG & GAGGAAGAGGCTTTGGGTCC & 141 & NM_001012956.2 \\
G6PC & AAGCCAAGCGAGGTGTGAGC & GGAACGGGACCACTTGCTGAG & 165 & NM_001113445 \\
\hline
\end{tabular}

GLP-2 - glucagon-like peptide-2, IGF-1 - insulin-like growth factor-1, MUC2 - mucin 2, OCLN - occludin, ZO1 - zonula occludens 1, INSR - insulin receptor, IRS1 - insulin receptor substrate 1, PI3KC3 - phosphatidylinositol 3-kinase catalytic subunit type 3, G6PC - glucose6-phosphatase

maltase, sodium/potassium ATPase $\left(\mathrm{Na}^{+}, \mathrm{K}^{+}\right.$-ATPase $)$ calcium/magnesium ATPase $\left(\mathrm{Ca}^{2+}, \mathrm{Mg}^{2+}\right.$-ATPase $)$ and creatine kinase $(\mathrm{CK})$ in jejunal mucosa, and carnitine palmitoyltransferase 1 (CPT-1), lipoprotein lipase (LPL), hepatic lipase (HL) and malate dehydrogenase $(\mathrm{MDH})$ in liver and longissimus dorsi muscle were determined using commercial kits (Nanjing Jiancheng Bioengineering Institute, Nanjing, China) according to the manufacturer's instructions. The total protein content in jejunum mucosa, liver and longissimus dorsi muscle homogenates were detected by Braford brilliant blue method (Chen et al., 2018). Each parameter was determined in duplicate simultaneously on the same plate. And the differences among parallels must have been small (coefficient of variation was less than $10 \%$ ) to guarantee the reproducibility of repeated measurements.

\section{Detection of mRNA expression}

Total RNA was isolated from frozen jejunum, colon, liver and longissimus dorsi muscle using Trizol reagent (TaKaRa, Dalian, China) according to the manufacturer's instructions. The concentration and purity of the RNA were determined using a NanoDrop ND-2000 Spectrophotometer (NanoDrop, Hilden, Germany). Ratios of $\mathrm{OD}_{260}: \mathrm{OD}_{280}$ ranging from 1.8 to 2.0 in all samples was regarded as suitable for further analysis. The integrity of RNA was detected by agarose gel electrophoresis and the 28S:18S ribosomal RNA band ratio was determined as $\geq 1.8$. RNA was reverse transcribed into cDNA using PrimeScript ${ }^{\mathrm{TM}}$ RT reagent kit (TaKaRa, Dalian, China) according to the manufacturer's guidelines. The mRNA expression of genes involved in the intestinal development (glucagon like peptide-2 (GLP2), insulin-like growth factor-1 (IGF1)), barrier functioning mucin 2 (MUC2), occludin $(O C L N)$, zonula occludens $1(\mathrm{ZOI})$ ) in jejunum and colon, and glucose metabolism (insulin receptor (INSR), insulin receptor substrate 1 (IRSI), phosphatidylinositol 3-kinase catalytic subunit type (PI3KC3), glucose-6-phosphatase (G6PC)) in longissimus dorsi muscle and liver was analysed with use of the Opticon DNA Engine (Bio-Rad, Hercules, CA, USA) and SYBR Green PCR reagents (TaKaRa, Dalian, China). Primers for the selected genes (Table 3 ) were designed by Primer 6 Software (PREMIER Biosoft International, Palo Alto, CA, USA) and synthesized commercially by Sangon Biotech Limited (Shanghai, China). Quantitative real-time PCR was performed on an ABI Prism 7000 detection system in a two-step protocol with SYBR Green (Applied Biosystems, Foster City, CA, USA). Each reaction was performed in a volume of $1 \mu \mathrm{l}$ cDNA, $5 \mu \mathrm{l}$ SYBR Premix Ex Taq TM ( $2 \times), 0.2 \mu \mathrm{l}$ ROX reference dye $(50 \times), 0.4 \mu \mathrm{l}$ each forward and reverse primer, and $3 \mu \mathrm{l}$ PCR-grade water. The PCR conditions were as follows: initial denaturation at $95{ }^{\circ} \mathrm{C}$ for $30 \mathrm{~s}$, followed by 40 cycles of denaturation at $95^{\circ} \mathrm{C}$ for $10 \mathrm{~s}$, annealing at $60^{\circ} \mathrm{C}$ for $25 \mathrm{~s}$ and $\mathrm{a} 72^{\circ} \mathrm{C}$ extension step for $5 \mathrm{~min}$. A melting curve analysis was generated following each realtime quantitative PCR assay to verify the specificity of the reactions. $\beta$-actin $(A C T B)$ was chosen as the reference gene to normalize mRNA expression of target genes. The relative expression ratio of the target gene in comparison with the reference gene was calculated using the $2^{-\Delta \Delta \mathrm{C}_{\mathrm{T}}}$ method (Pfaffl, 2001). The relative expression of target genes in T1 diet group was set to be 1.0. Each sample was measured in triplicate.

\section{Statistical analysis}

In the current study, the individual piglet was used as the experimental unit. The data were subjected to the GLM procedure of SAS ver. 9.2 (SAS Institute, Inc., Cary, NC, USA). Differences among treatments were determined by Duncan's multiple 
comparison. All differences were considered significant at $P<0.05$, whereas $P$-values between 0.05 and 0.1 were considered a trend. All data are presented as means and standard error of the mean (SEM).

\section{Results}

\section{The relative mRNA expression of intestinal development related genes}

As shown in Table 4, no difference was observed on the mRNA expression of intestinal development related genes in jejunum $(P>0.05)$, but the mRNA expression of GLP2 in T1 group was more than twice as high as that in T3 group. Meanwhile, the mRNA expression of GLP2 in colon in T1 group was increased $(P<0.05)$ in comparison to T3 group, and the mRNA expression of $I G F 1$ in T1 group tended to be greater $(P=0.06)$ than that in T3 group.

Table 4. Effects of different combinations of carbohydrates on the mRNA expression of genes related to intestinal development in jejunum and colon of weaned pigs

\begin{tabular}{|c|c|c|c|c|c|}
\hline \multirow{2}{*}{ Genes } & \multicolumn{3}{|c|}{$\begin{array}{l}\text { Diets with different combinations } \\
\text { of carbohydrates }\end{array}$} & \multirow{2}{*}{ SEM } & \multirow{2}{*}{$P$-value } \\
\hline & $\overline{\mathrm{T} 1}$ & $\mathrm{~T} 2$ & T3 & & \\
\hline \multicolumn{6}{|l|}{ Jejunum } \\
\hline GLP2 & 1.00 & 0.77 & 0.42 & 0.18 & 0.11 \\
\hline IGF1 & 1.00 & 1.08 & 0.86 & 0.15 & 0.56 \\
\hline \multicolumn{6}{|l|}{ Colon } \\
\hline GLP2 & $1.00^{a}$ & $0.95^{\mathrm{ab}}$ & $0.61^{b}$ & 0.10 & 0.02 \\
\hline IGF1 & 1.00 & 0.86 & 0.43 & 0.15 & 0.06 \\
\hline $\begin{array}{l}\text { T1, T2, } \\
\text { IGF1 - ins } \\
\text { ab - mear } \\
\text { different a }\end{array}$ & in a & 1 & $\begin{array}{l}\text { - glu } \\
\text { - stand } \\
\text { supers }\end{array}$ & $\begin{array}{l}\text {-like } \\
\text { ror of } \\
\text { are si }\end{array}$ & $\begin{array}{l}\text { eptide-2 } \\
\text { he mean; } \\
\text { nificantly }\end{array}$ \\
\hline
\end{tabular}

\section{The activities of digestive and absorptive related enzymes in jejunum}

As presented in Table 5, T1 diet enhanced $(P<0.05)$ the activity of lactase in comparison to T2 group, while it was not relatively different from T3 group $(P>0.05)$. Intriguingly, both activities of digestive enzymes (amylase, trypsin, lactase, sucrase and maltose) and absorptive enzymes $\left(\mathrm{CK}, \mathrm{Na}^{+}, \mathrm{K}^{+}-\right.$ ATPase and $\mathrm{Ca}^{2+}, \mathrm{Mg}^{2+}$-ATPase) did not differ between groups, except lactose activity that was lower in $\mathrm{T} 2$ group in comparison to $\mathrm{T} 1$ and $\mathrm{T} 3$ groups.

\section{The relative mRNA expressions of intestinal barrier related genes}

As shown in Table 6, no difference was found in the mRNA expressions of barrier function related genes in jejunum $(P>0.05)$. Whereas, the mRNA expressions of $Z O 1$ and $O C L N$ in colon of T1 group were markedly increased $(P<0.05)$ in comparison to $\mathrm{T} 3$ group.
Table 5. Effects of different combinations of carbohydrates on digestive and absorptive enzyme activity in jejunum of weaned pigs

\begin{tabular}{|c|c|c|c|c|c|}
\hline \multirow[t]{2}{*}{ Activities } & \multicolumn{3}{|c|}{$\begin{array}{l}\text { Diets with different } \\
\text { combinations } \\
\text { of carbohydrates }\end{array}$} & \multirow[t]{2}{*}{ SEM } & \multirow[t]{2}{*}{$P$-value } \\
\hline & T1 & $\mathrm{T} 2$ & T3 & & \\
\hline Amylase, U/mg protein & 0.50 & 0.47 & 0.45 & 0.06 & 0.80 \\
\hline Trypsin, U/mg protein & 82.0 & 80.8 & 70.5 & 5.64 & 0.32 \\
\hline Maltase, $\mathrm{U} / \mathrm{mg}$ protein & 344 & 230 & 250 & 45.44 & 0.22 \\
\hline Sucrase, $\mathrm{U} / \mathrm{mg}$ protein & 114.6 & 67.5 & 86.1 & 21.44 & 0.33 \\
\hline Lactase, $\mathrm{U} / \mathrm{mg}$ protein & $48.9^{a}$ & $27.6^{\mathrm{b}}$ & $46.9^{a}$ & 4.64 & 0.01 \\
\hline Creatine kinase, $\mathrm{U} / \mathrm{mg}$ protein & 1.66 & 1.59 & 1.33 & 0.26 & 0.66 \\
\hline $\begin{array}{l}\mathrm{Na}^{+}, \mathrm{K}^{+}-\mathrm{ATP} a s e, \mathrm{molPi} / \mathrm{mg} \\
\text { protein/h }\end{array}$ & 6.35 & 5.29 & 5.89 & 0.48 & 0.33 \\
\hline $\begin{array}{l}\mathrm{Ca}^{2+}, \mathrm{Mg}^{2+}-\mathrm{ATP} a s e, \text { molPi/mg } \\
\text { protein/h }\end{array}$ & 6.34 & 5.18 & 5.41 & 0.58 & 0.36 \\
\hline
\end{tabular}

T1, T2, T3 - see Table 1; $\mathrm{Na}^{+}, \mathrm{K}^{+}$-ATPase - sodium/potassium ATPase, $\mathrm{Ca}^{2+}, \mathrm{Mg}^{2+}$-ATPase - calcium/magnesium ATPase; SEM - standard error of the mean; ab - means within a row with different superscripts are significantly different at $P<0.05$

Table 6. Effects of different combinations of carbohydrates on the mRNA expression of tight junction-related genes, mucin and inflammatory factors in jejunum and colon of weaned pigs

\begin{tabular}{cccccc}
\hline \multirow{5}{*}{ Genes } & \multicolumn{3}{l}{$\begin{array}{l}\text { Diets with different } \\
\text { of carbohydrates }\end{array}$} & SEM & $P$-value \\
\cline { 2 - 4 } & T1 & T2 & T3 & & \\
\hline Jejunum & & & & & \\
ZO1 & 1.00 & 0.80 & 0.68 & 0.12 & 0.20 \\
OCLN & 1.00 & 1.21 & 0.91 & 0.11 & 0.18 \\
MUC2 & 1.00 & 0.75 & 0.68 & 0.10 & 0.12 \\
Colon & & & & & \\
ZO1 & $1.00^{\mathrm{a}}$ & $0.98^{\mathrm{ab}}$ & $0.77^{\mathrm{b}}$ & 0.05 & 0.02 \\
OCLN & $1.00^{\mathrm{a}}$ & $0.91^{\mathrm{ab}}$ & $0.64^{\mathrm{b}}$ & 0.08 & 0.02 \\
MUC2 & 1.00 & 1.38 & 0.93 & 0.18 & 0.20 \\
\hline
\end{tabular}

T1, T2, T3 - see Table 1; ZO1 - zonula occludens 1, OCLN - occludin, MUC2 - mucin 2; SEM - standard error of the mean; ${ }^{\text {ab }}$ - means within a row with different superscripts are significantly different at $P<0.05$

\section{The activities of lipid metabolism enzymes in liver and longissimus dorsi muscle}

The activities of enzymes associated with lipid metabolism are demonstrated in Table 7. The activities of lipid metabolism enzymes in liver were not influenced by treatments $(P>0.05)$. However, in comparison to T2 and T3 groups, the LPL activity in longissimus dorsi muscle in T1 group was the lowest $(P<0.05)$. Meanwhile, pigs from T1 group tended to have higher $(P=0.07) \mathrm{MDH}$ activity in longissimus dorsi muscle.

\section{The relative mRNA expression of glucose metabolism related genes in liver and longissimus dorsi muscle}

As presented in Table 8, the mRNA expression of IRSI and G6PC in liver were significantly influenced by treatments $(P<0.05)$. And, T1 group 
Table 7. Effects of different combinations of carbohydrates on enzyme activity in liver and longissimus dorsi muscle of weaned pigs

\begin{tabular}{|c|c|c|c|c|c|}
\hline \multirow[t]{2}{*}{ Indices } & \multicolumn{3}{|c|}{$\begin{array}{l}\text { Diets with different combinations } \\
\text { of carbohydrates }\end{array}$} & \multirow[t]{2}{*}{ SEM } & \multirow[t]{2}{*}{$P$-value } \\
\hline & $\overline{\mathrm{T} 1}$ & $\mathrm{~T} 2$ & T3 & & \\
\hline \multicolumn{6}{|l|}{ Liver } \\
\hline CPT-1, ng/l & 203 & 184 & 190 & 6.81 & 0.16 \\
\hline LPL, U/mg protein & 0.48 & 0.50 & 0.56 & 0.03 & 0.16 \\
\hline $\mathrm{HL}, \mathrm{U} / \mathrm{mg}$ protein & 0.41 & 0.39 & 0.45 & 0.03 & 0.46 \\
\hline $\mathrm{MDH}, \mathrm{U} / \mathrm{mg}$ protein & 3.95 & 4.17 & 6.42 & 1.44 & 0.43 \\
\hline \multicolumn{6}{|c|}{ Longissimus dorsi muscle } \\
\hline CРT-1, ng/l & 155 & 156 & 148 & 4.02 & 0.33 \\
\hline LPL, U/mg protein & $0.27^{b}$ & $0.47^{\mathrm{a}}$ & $0.50^{a}$ & 0.04 & $<0.01$ \\
\hline $\mathrm{HL}, \mathrm{U} / \mathrm{mg}$ protein & 0.30 & 0.42 & 0.27 & 0.09 & 0.46 \\
\hline $\mathrm{MDH}, \mathrm{U} / \mathrm{mg}$ protein & 4.07 & 4.02 & 3.38 & 0.21 & 0.07 \\
\hline
\end{tabular}

T1, T2, T3 - see Table 1; CPT-1 - carnitine palmitoyltransferase 1, $\mathrm{LPL}$ - lipoprotein lipase, $\mathrm{HL}$ - hepatic lipase, $\mathrm{MDH}$ - malate dehydrogenase; SEM - standard error of the mean; ${ }^{\text {ab }}$ - means within a row with different superscripts are significantly different at $P<0.05$

Table 8. Effects of different combinations of carbohydrates on the mRNA expression of glucose metabolism related genes in liver and longissimus dorsi muscle of weaned pigs

\begin{tabular}{cccccc}
\hline \multirow{5}{*}{ Genes } & \multicolumn{3}{l}{$\begin{array}{l}\text { Diets with different combinations } \\
\text { of carbohydrates }\end{array}$} & SEM & P-value \\
\cline { 2 - 4 } & T1 & T2 & T3 & & \\
\hline Liver & & & & & \\
INSR & 1.00 & 1.21 & 0.98 & 0.21 & 0.13 \\
IRS1 & $1.00^{\mathrm{a}}$ & $0.74^{\mathrm{ab}}$ & $0.67^{\mathrm{b}}$ & 0.13 & 0.03 \\
PIK3C3 & 1.00 & 1.00 & 0.92 & 0.14 & 0.88 \\
G6PC & $1.00^{\mathrm{a}}$ & $0.55^{\mathrm{b}}$ & $0.45^{\mathrm{b}}$ & 0.16 & 0.04 \\
Longissimus dorsi muscle & & & \\
INSR & 1.00 & 1.14 & 1.32 & 0.10 & 0.12 \\
IRS1 & 1.00 & 0.96 & 1.21 & 0.11 & 0.24 \\
PIK3 & 1.00 & 0.91 & 1.20 & 0.19 & 0.56 \\
G6PC & 1.00 & 0.72 & 0.83 & 0.18 & 0.11 \\
\hline
\end{tabular}

T1, T2, T3 - see Table 1; INSR - insulin receptor, IRS1 - insulin receptor substrate 1, PI3KC3 - phosphatidylinositol 3-kinase catalytic subunit type 3, G6PC - glucose-6-phosphatase; SEM - standard error of the mean; ${ }^{a b}$ - means within a row with different superscripts are significantly different at $P<0.05$

exhibited the highest mRNA expression of IRSI and $G 6 P C$ in liver among the treatments $(P<0.05)$. Furthermore, there were similarities in mRNA expression of glucose metabolism related genes in longissimus dorsi muscle $(P>0.05)$.

\section{Discussion}

In the modern swine industry, piglets often encounter physiological, social and nutritional stresses, in particular during the weaning period (Kim et al., 2012). Those stressful events profoundly influences piglet health and lead to growth retardation, diarrhoea and sometimes mortality (Campbell et al., 2013).
In addition to using certain nutrients against the detrimental impacts (de Lange et al., 2010), it is important to develop ways to obtain a better animal health with other means. One possible way is to use various dietary interventions by changing the diet composition. In the present study it was shown that animals fed appropriate combination of dietary starch and NSP, i.e. starch with AM/ $\mathrm{AP}$ in a ratio of 1:1 (the total quantities of $\mathrm{AM}$ and AP in the diet were $19.68 \%$ and $19.79 \%$, respectively) and NSP 3\% (a mixture of inulin and cellulose in a ratio of 1:1), exhibited higher growth performance and nutrients digestibility, and lower diarrhoea incidences. Moreover, in pigs fed this combination the concentration of butyrate in serum was significantly increased, contents of acetate and propionate in cecum and colon were reduced, and the abundance of butyrate-producing bacteria was markedly increased (unpublished data). Being in line with our previous work, the present study demonstrates that the optimal combination of starch and NSP may also improve the intestinal functions, and lipid and glucose metabolism of pigs.

It is noteworthy, that in the present study the mRNA expression of GLP2 in colon of $\mathrm{T} 1$ group significantly increased in comparison to T3 group. In addition, the mRNA expression of $I G F-1$ in colon of $\mathrm{T} 1$ group tended to be enhanced in comparison to T3 group. It is known that GLP2 is a critical regulator of intestinal development, digestion and absorption, and integrity of intestine (Bloom and Polak, 1982). Likewise, $I G F 1$ is an important growth factor of gastrointestinal tract and plays a vital role in mammalian growth and development (Xiao et al., 2009). It suggests that $\mathrm{T} 1$ diet may promote intestinal development as compared to T3 diet (AM/AP ratio of 1:1 in $\mathrm{T} 1$ diet is higher than the AM/AP ratio of $1: 2$ in T3 diet). Consistently, in the our previous study we have reported up-regulated mRNA expression of GLP2 and IGF1 in piglets fed higher $\mathrm{AM} / \mathrm{AP}$ ratio in starch diet (Han et al., 2012). Yet, the mRNA expressions of GLP2 and IGF1 in T2 group (AM/AP ratio of 2:1) were similar to those in T1 group. Intriguingly, the mRNA expression of GLP2 both in jejunum and colon in T1 group was numerically greater than those in $\mathrm{T} 2$ group. It may be connected with the lower content of NSP in T2 diet than that in T1 diet, as diet supplementation with moderate level of dietary fibre is necessary to maintain the normal physiological function of gastrointestinal tract and boosts gut health of the host (Wenk, 2001). With a rapid growth and a high metabolic rate, piglets require a large amount of nutrients. 
Decreased digestion and absorption function will impair growth performance. Thus, a greater activity of digestion and absorption enzymes is vital for nutrient absorption and body growth. In the current study, the activity of lactase in $\mathrm{T} 1$ group was significantly higher than that in T2 group, while it was similar with that in T3 group. Nevertheless, consistently with our previous study, both the greatest activities of digestive and absorptive enzymes were observed in the animals fed T1 diet (data unpublished). Noteworthy, the tight junction proteins (ZO1 and OCLN) maintain the intestinal barrier integrity by efficient prevention of the diffusion of bacteria and other antigens through the epithelium (Ulluwishewa et al., 2011). We have shown that mRNA expression of $\mathrm{ZOI}$ and $O C L N$ in colon of $\mathrm{T} 1$ group were markedly higher than those of T3 group, indicating that T1 diet is more beneficial for intestinal barrier functioning than T3 diet. The increase in ZOI and OCLN mRNA levels in colon might be caused by the content of AM and NSP, since the ratio of AM/AP and the concentration of NSP in T1 diet were higher than in T3 diet. Dietary fibre (e.g., NSP and resistant starch) is the substrate for gastrointestinal microflora fermentation into SCFAs, which promotes the intestinal epithelial barrier function (Chen et al., 2013; Morrison and Preston, 2016). Indeed, the content of butyrate in serum of $\mathrm{T} 1$ group was significantly higher than that obtained in our previous study (data unpublished). Likewise, the gut microbiota provides essential capacities for the fermentation of dietary fibre into SCFAs, which could alleviate the weaning-induced damage to intestinal structural integrity by promoting the tight junction protein expression levels in weaned pigs (Diao et al., 2019). Indeed, the content of butyrate in serum of T1 group was significantly higher than that obtained in our previous study (data unpublished). Intriguingly, the content of NSP in $\mathrm{T} 2$ diet was lower than in $\mathrm{T} 1$ diet, while no differences were observed in the mRNA expression of $\mathrm{ZOI}$ and $O C L N$ between $\mathrm{T} 1$ and $\mathrm{T} 2$ groups, possibly due to the content of AM in T2 diet was greater than in T1 diet. Hence, feeding with T1 diet (starch with AM/AP ratio of 1:1 and NSP 3\%) may positively influence the intestinal functions via promoting the mRNA expression of genes related to intestinal development and barrier function and increasing the activities of digestive and absorptive enzymes to some extent.

Carbohydrates can be metabolized by the microbiota through the enzymatic degradation of glycosidic linkages and the fermentation of liberated monosaccharides into SCFAs (Wong et al., 2006). Moreover, in our previous study we have indicated that greater production of SCFAs correlates with lower diet-induced obesity (Lin et al., 2012). Propionate can be largely converted to glucose (gluconeogenesis) in liver by entering tricarboxylic acid (TCA) cycle (Bloemen et al., 2010; den Besten et al., 2013). Acetate also can be changed into substrates for the synthesis of cholesterol and long-chain fatty acids (den Besten et al., 2013). Importantly, in our previous work we have observed markedly lower concentration of acetate in caecum and colon of T1 group than in other treatments (data unpublished). Thus, feeding with T1 diet might ameliorate lipid metabolism and reduce fat deposition in liver of pigs. Correspondingly, the greatest activity of CPT-1 in liver of T1 group was detected, since CPT- 1 is the rate-limiting enzyme that determines fatty acid oxidation (Snel et al., 2012). Mohamed et al. (2019) have shown that a fibre-supplemented diet could reduce hepatic lipid storage in pigs. Hence, the beneficial effect of T1 diet on lipid metabolism may be related to the highest content of NSP in T1 diet. Likewise, in animals fed diet with lower AM/AP ratio hepatic lipid deposit was enhanced (Yang et al., 2018). Meanwhile, in the present study the activity of LPL in longissimus dorsi muscle of $\mathrm{T} 1$ group was apparently decreased. As LPL catalyses the hydrolysis of triglycerides residing in chylomicrons, thus providing free fatty acid for tissue utilization (Mead et al., 2003). It may appear that starch diet with AM/AP ratio of $1: 1$ and NSP $3 \%$ to some extent may decrease lipid deposition of pigs. On the other hand, the liver is the major organ with the ability to consume, store and produce glucose. Hepatic glucose metabolism includes the formation of glycogen, generation of glucose from non-sugar carbon substrates by gluconeogenesis and intracellular energy supply via glycolysis. Zhao et al. (2018) have reported that greater production of SCFAs could increase insulin sensitivity. Intriguingly, the abundance of Firmicutes, a predominant butyrate-producing bacteria (Louis and Flint, 2017), in T1 group was increased. Also, the content of butyrate in serum of $\mathrm{T} 1$ group was remarkably higher than of other treatments (data unpublished). Notably, butyrate is particularly important as the main energy source for colonocytes, and can activate intestinal gluconeogenesis, having beneficial effects on glucose and energy homeostasis (De Vadder et al., 2014). Herein, T1 diet may improve the glucose metabolism in pigs. Indeed, in the current study we have observed that the mRNA expression of IRS1 in liver of T1 group was significantly upregulated. The insulin receptor substrates bind to the activated insulin receptor, then are phosphorylated, 
thereby providing docking sites for a multitude of signalling molecules, essential for the diversification and regulation of insulin action, and hence for the tight modulation of the hepatic glucose (Fritsche et al., 2008). Moreover, the activity of MDH in longissimus dorsi muscle tended to be increased and the mRNA expression of G6PC in liver of T1 group was markedly up-regulated in comparison to T2 and T3 groups. MDH plays an important role in the Krebs cycle, and is involved in the oxidation of glucose to produce ATPs (Donnelly et al., 2005). The $G 6 P C$, a key enzyme in glucose homeostasis, catalyzes the hydrolysis of glucose-6-phosphate to glucose and phosphate in the final step of gluconeogenesis (Chou and Mansfield, 2010). Therefore, the diet containing starch with AM/AP ratio of 1:1 and NSP 3\% may improve glucose control in liver.

\section{Conclusions}

For the first time it was shown that the intestinal functions in pigs were significantly influenced by different combinations of starch and non-starch polysaccharides (NSP), and lipid and glucose metabolisms were affected to some extent. Animals fed diet containing starch with amylose/amylopectin (AM/AP) ratio of 1:1 and NSP 3\% (a mixture of inulin and cellulose in ratio $1: 1$ ) were characterised by better intestinal functions, attenuated fat deposition and ameliorated glucose metabolism in liver and to some extent in longissimus dorsi muscle. So, the combination diet exhibits a novel way of evaluation the carbohydrate quality of the entire diet and provides a prerequisite foundation for further investigations of more diverse carbohydrates diet for animals and humans.

\section{Acknowledgements}

This study was supported by National Natural Science Foundation of China (31730091) and the National Key Research and Development Program of China (2017YFD0500503).

\section{References}

AOAC International, 1995. Official Methods of Analysis of AOAC International. $16^{\text {th }}$ Edition. Arlington, VA (USA)

Aumiller T., Mosenthin R., Weiss E., 2015. Potential of cereal grains and grain legumes in modulating pigs' intestinal microbiota - A review. Livest. Sci. 172, 16-32, https://doi.org/10.1016/j. livsci.2014.11.016

Bach Knudsen K.E., 2011. Triennial Growth Symposium: Effects of polymeric carbohydrates on growth and development in pigs. J. Anim. Sci. 89, 1965-1980, https://doi.org/10.2527/ jas.2010-3602
Behall K.M., Scholfield D.J., 2005. Food amylose content affects postprandial glucose and insulin responses. Cereal Chem. 82, 654-659, https://doi.org/10.1094/CC-82-0654

Bloemen J.G., Olde Damink S.W.M., Venema K., Buurman W.A., Jalan R., Dejong C.H.C., 2010. Short chain fatty acids exchange: Is the cirrhotic, dysfunctional liver still able to clear them? Clin. Nutr. 29, 365-369, https://doi.org/10.1016/j.clnu.2009.10.002

Bloom S.R., Polak J.M., 1982. The hormonal pattern of intestinal adaptation. A major role for enteroglucagon. Scand. J. Gastroenterol. Suppl. 74, 93-103

Bosaeus I., 2004. Fibre effects on intestinal functions (diarrhoea, constipation and irritable bowel syndrome). Clin. Nutr. Suppl. 1, 33-38, https://doi.org/10.1016/j.clnu.2004.09.006

Campbell J., Crenshaw J., Polo J., 2013. The biological stress of early weaned piglets. J. Anim. Sci. Biotechnol. 2, 45-48, https://doi. org/https://doi.org/10.1186/2049-1891-4-19

Chen H., Mao X.B., He J., Huang Z., Yu J., Zheng P., Chen D., 2013. Dietary fibre affects intestinal mucosal barrier function and regulates intestinal bacteria in weaning piglets. Br. J. Nutr. 110 , 1837-1848, https://doi.org/10.1017/S0007114513001293

Chen H., Mao X.B., Yin J., He J., Huang Z., Zheng P., Chen D., 2015. Comparison of jejunal digestive enzyme activities, expression of nutrient transporter genes, and apparent fecal digestibility in weaned piglets fed diets with varied sources of fiber. J. Anim. Feed Sci. 24, 41-47, https://doi.org/10.22358/ jafs/65651/2015

Chen J., Li Y., Yu B., Chen D.W., Mao X.B., Zheng P., Luo J.Q., He J., 2018. Dietary chlorogenic acid improves growth performance of weaned pigs through maintaining antioxidant capacity and intestinal digestion and absorption function. J. Anim. Sci. 96, 1108-1118, https://doi.org/10.1093/jas/skx078

Chen T.T., Chen D.W., Tian G. et al., 2019. Effects of soluble and insoluble dietary fiber supplementation on growth performance, nutrient digestibility, intestinal microbe and barrier function in weaning piglet. Anim. Feed. Sci. Technol. 260, 114335, https://doi.org/10.1016/j.anifeedsci.2019.114335

Chou J.Y., Mansfield B.C., 2010. Mutations in the glucose-6-phosphatase-alpha (G6PC) gene that cause type la glycogen storage disease. Hum. Mutat. 29, 921-930, https://doi.org/10.1002/ humu.20772

de Lange C.F.M., Pluske J., Gong J., Nyachoti C.M., 2010. Strategic use of feed ingredients and feed additives to stimulate gut health and development in young pigs. Livest. Sci. 134, 124-134, https://doi.org/10.1016/j.livsci.2010.06.117

De Vadder F., Kovatcheva-Datchary P., Goncalves D. et al., 2014. Microbiota-generated metabolites promote metabolic benefits via gut-brain neural circuits. Cell 156, 84-96, https://doi. org/10.1016/j.cell.2013.12.016

den Besten G., Lange K., Havinga R. et al., 2013. Gut-derived shortchain fatty acids are vividly assimilated into host carbohydrates and lipids. Am. J. Physiol. Gastrointest. Liver. Physiol. 305, G900-G910, https://doi.org/10.1152/ajpgi.00265.2013

Diao H., Jiao A., Yu B., Mao X., Chen D.W., 2019. Gastric infusion of short-chain fatty acids can improve intestinal barrier function in weaned piglets. Genes. Nutr. 14, 3-16, https://doi. org/10.1186/s12263-019-0626-x

Donnelly K.L., Smith C.I., Schwarzenberg S.J., Jessurun J., Boldt M.D., Parks E.J., 2005. Sources of fatty acids stored in liver and secreted via lipoproteins in patients with nonalcoholic fatty liver disease. J. Clin. Invest. 115, 1343-1351, https://doi. org/10.1172/JCl23621

Flint H.J., Scott K.P., Louis P., Duncan S.H., 2012. The role of the gut microbiota in nutrition and health. Nat. Rev. Gastroenterol. Hepatol. 9, 577-589, https://doi.org/10.1038/nrgastro.2012.156 
Fritsche L., Weigert C., Haring H.U., Lehmann R., 2008. How insulin receptor substrate proteins regulate the metabolic capacity of the liver implications for health and disease. Curr. Med. Chem. 15, 1316-1329, https://doi.org/10.2174/092986708784534956

Han G.Q., Xiang Z.T., Yu B., Chen D.W., Qi H.W., Mao X.B., Chen H., Mao Q., Huang Z.Q., 2012. Effects of different starch sources on Bacillus.spp. in intestinal tract and expression of intestinal development related genes of weanling piglets. Mol. Biol. Rep. 39, 1869-1876, https://doi.org/10.1007/s11033-011-0932-x

Han H., Zhang K., Ding X., Bai S., Luo Y., Wang J., Peng H., Zeng Q., 2016. Effects of dietary nanocrystalline cellulose supplementation on growth performance, carcass traits, intestinal development and lipid metabolism of meat ducks. Anim. Nutr. 2, 192-197, https:// doi.org/10.1016/i.aninu.2016.06.004

He J., Chen D., Yu B., 2010. Metabolic and transcriptomic responses of weaned pigs induced by different dietary amylose and amylopectin ratio. PLoS ONE. 5, e15110, https://doi.org/10.1371/ journal.pone.0015110

Ichimura A., Hirasawa A., Hara T., Tsujimoto G., 2009. Free fatty acid receptors act as nutrient sensors to regulate energy homeostasis. Prostaglandins Other Lipid. Mediat. 89, 82-88, https://doi. org/10.1016/j.prostaglandins.2009.05.003

Jha R., Berrocoso J.D., 2015. Review: Dietary fiber utilization and its effects on physiological functions and gut health of swine. Animal 9, 1441-1452, https://doi.org/10.1017/S1751731115000919

Kim J.C., Hansen C., Mullan B., Pluske J., 2012. Nutrition and pathology of weaner pigs: Nutritional strategies to support barrier function in the gastrointestinal tract. Anim. Feed. Sci. Technol. 173 3-16, https://doi.org/10.1016/j.anifeedsci.2011.12.022

Kumar V., Sinha A.K., Makkar H.P.S., de Boeck G., Becker K., 2012. Dietary roles of non-starch polysachharides in human nutrition: A Review. Crit. Rev. Food. Sci. Nutr. 52, 899-935, https://doi.or g/10.1080/10408398.2010.512671

Li Y.J., Li J.L., Zhang L., Gao F., 2017. Effects of dietary starch types on growth performance, meat quality and myo-fibre type of finishing pigs. Meat Sci. 131, 60-67, https://doi.org/10.1016/j. meatsci.2017.04.237

Lin H.V., Frassetto A., Kowalik E.J. et al., 2012. Butyrate and propionate protect against diet-induced obesity and regulate gut hormones via free fatty acid receptor 3 -independent mechanisms. PloS ONE 7, e35240, https://doi.org/10.1371/journal.pone.0035240

Lindberg J.E., 2014 Fiber effects in nutrition and gut health in pigs. J. Anim. Sci. Biotechnol. 5, 273-279, https://doi. org/10.1186/2049-1891-5-15

Louis P., Flint H.J., 2017. Formation of propionate and butyrate by the human colonic microbiota. Environ. Microbiol. 19, 29-41, https://doi.org/10.1111/1462-2920.13589

Mead J.R., Irvine S., Ramji D., 2003. Lipoprotein lipase: Structure, function, regulation, and role in disease. J. Mol. Med. (Ber) 80, 753-769, https://doi.org/10.1007/s00109-002-0384-9

Mohamed A.B., Rémond D., Chambon C., et al., 2019. A mix of dietary fermentable fibers improves lipids handling by the liver of overfed minipigs. J. Nutr. Biochem. 65, 72-82, https://doi.org/10.1016/j.jnutbio.2018.12.002

Morrison D.J., Preston T., 2016. Formation of short chain fatty acids by the gut microbiota and their impact on human metabolism. Gut Microbes 7, 1-12, https://doi.org/10.1080/19490976.2015.11 34082

NRC (National Research Council), 2012. Nutrient Requirements of Swine. $11^{\text {th }}$ Revised Edition. The National Academies Press. Washington, DC (USA), https://doi.org/10.17226/13298
Pfaffl M.W., 2001. A new mathematical model for relative quantification in real-time RT-PCR. Nucleic Acids Res. 29, 900-905, https:// doi.org/10.1093/nar/29.9.e45

Regmi P.R., Matte J.J., Ganzle M.G., van Kempen T.A., Zijlstra R.T., 2010. Starch chemistry affects kinetics of glucose absorption and insulin response in swine. Livest. Sci. 134, 44-46, https://doi.org/10.1016/j.livsci.2010.06.092

Regmi P.R., Metzler-Zebeli B.U., Ganzle M.G., van Kempen T.A., Zijlstra R.T., 2011. Starch with high amylose content and low in vitro digestibility increases intestinal nutrient flow and microbial fermentation and selectively promotes bifidobacteria in pigs. J. Nutr. 141, 1273-1280, https://doi. org/10.3945/jn.111.140509

Singh J., Dartois A., Kaur L., 2010. Starch digestibility in food matrix: a review. Trends Food Sci. Technol. 21, 168-180, https://doi. org/10.1016/j.tifs.2009.12.001

Snel M., Jonker J.T., Schoones J., Lamb H., de Roos A., Pijl H., Smit J.W., Meinders A.E., Jazet I.M., 2012. Ectopic fat and insulin resistance: pathophysiology and effect of diet and lifestyle interventions. Int. J. Endocrinol. 2012, 983-814, https://doi.org/10.1155/2012/983814

Ulluwishewa D., Anderson R.C., Mcnabb W.C., Moughan P.J., Wells J.M., Roy N.C., 2011. Regulation of tight junction permeability by intestinal bacteria and dietary components. J. Nutr. 141, 769-776, https://doi.org/10.3945/jn.110.135657

Wang H.J., Pu J.N., Chen D.W., Tian G., Mao X.B., 2019. Effects of dietary amylose and amylopectin ratio on growth performance, meat quality, postmortem glycolysis and muscle fibre type transformation of finishing pigs. Arch. Anim. Nutr. 73, 194-207, https://doi.org/10.1080/1745039X.2019.1583518

Wenk C., 2001. The role of fiber in digestive physiology of the pig. Anim. Feed Sci. Technol. 90, 21-33, https://doi.org/10.1016/ S0377-8401(01)00194-8

Wong J.M., de Souza R., Kendall C.W., Emam A., Jenkins D.J., 2006. Colonic health: fermentation and short chain fatty acids. J. Clin. Gastroenterol. 40, 235-243, https://doi. org/10.1097/00004836-200603000-00015

Wu X., Chen D., Yu B., Luo Y., Zheng P., Mao X., Yu J., He J., 2018. Effect of different dietary non-starch fiber fractions on growth performance, nutrient digestibility, and intestinal development in weaned pigs. Nutrition 51-52, 20-28, https:/ doi.org/10.1016/j.nut.2018.01.011

Xiang Z.T., Qi H.W., Han G.Q. et al., 2011. Real-time TaqMan polymerase chain reaction to quantify the effects of different sources of dietary starch on Bifidobacterium in the intestinal tract of piglets. Afr. J. Biotechnol. 10, 5059-5067, https://doi. org/10.1186/1475-2859-10-44

Xiao S., Li S., Zhang J. et al., 2009. Cloning and characterization of class 1 and class 2 insulin-like growth factor-I mRNA in Songliao black pig. Mol. Biol. Rep. 36, 415-421, https://doi. org/10.1007/s11033-007-9195-y

Yang C., He J., Yu B., Yu J., Mao X.B., Chen D.W., Yin Y.L., 2018. The effect of dietary amylose/amylopectin ratio on serum and hepatic lipid content and its molecular mechanisms in growingfinishing pigs. J. Anim. Physiol. Anim. Nutr. 102, 1657-1665, https://doi.org/10.1111/jpn.12884

Zhao L., Zhang F., Ding X. et al., 2018. Gut bacteria selectively promoted by dietary fibers alleviate type 2 diabetes. Science 359, 1151-1156, https://doi.org/10.1126/science.aao5774 